Western North American Naturalist 70(2), (C) 2010, pp. 208-217

\title{
MINERAL LICK USE BY GPS RADIO-COLLARED MOUNTAIN GOATS IN SOUTHEASTERN BRITISH COLUMBIA
}

\author{
Kim G. Poole ${ }^{1,2}$, Karl D. Bachmann ${ }^{3,4}$, and Irene E. Teske ${ }^{5}$
}

\begin{abstract}
In most populations of mountain goats (Oreamnos americanus), mineral lick use is an essential part of the ecology of the species. In many areas, the distribution and use of licks in the landscape is poorly known, rendering planning for resource development difficult. We examined lick use by 28 GPS radio-collared mountain goats in 2 study areas in southeastern British Columbia during 2004-2005. Viewing collar-location movements on digital orthophotos, we assumed goat use of 6 previously known and 10 suspected mineral licks. Field visits verified that 9 of the 10 suspected sites were mineral licks. Thirteen of the 15 licks used by collared goats were within forests with commercial harvesting potential. All but 3 of the licks were $\leq 600 \mathrm{~m}$ from the closest logging block, and 5 licks were $<100 \mathrm{~m}$ away. Number of annual visits to licks by individual goats ranged from 0 to 9 . Goats often moved considerable distances (up to $17.3 \mathrm{~km}$ ) to visit licks. Most visits by males occurred between early May and late June (median 9 June), and most visits by females occurred between early June and mid-July (median 21 June). Mean time spent at licks on each visit was 1.5 days for females and 1.6 days for males. Most of the licks were characterized by numerous cavities dug under trees (which we term "lick trees"). Using GPS collars, we were able to collect data on lower-elevation mineral licks not previously known to researchers.
\end{abstract}

Key words: mountain goat, Oreamnos americanus, mineral licks, lick trees, GPS radio-collars, British Columbia, Rocky Mountains, Purcell Mountains.

Mineral licks (hereafter, licks) are used by all North American species of ungulates (Jones and Hanson 1985, Klaus and Schmid 1998) and are habitat features that appear to be critical to the health of populations. Many species of ungulates travel long distances (often outside of their typical habitats) to licks and may concentrate at high densities at licks (e.g., moose [Alces alces]_Tankersley and Gasaway 1983; Dall's sheep [Ovis dalli]_Tankersley 1984; and bighorn sheep [O. canadensis]—Watts and Schemnitz 1985).

Most populations of mountain goats (Oreamnos americanus) make extensive use of natural licks, often traveling to low-elevation sites or areas beyond their usual home ranges. A great deal of individual variation exists among goats in frequency, timing, and duration of lick visits, as well as distance traveled to access licks (Hebert and Cowan 1971, Singer and Doherty 1985, Hopkins et al. 1992, Klaus and Schmid 1998, Glasgow et al. 2003, Poole and Heard 2003, Ayotte et al. 2008). Lick use occurs primarily between April and early autumn, with males generally using licks earlier in the year and females and family groups beginning to use licks in early June (Hebert and Cowan 1971, Ayotte et al. 2008). Goats generally travel along traditional trails to access licks. These trails often traverse extensive forest areas, and goats may stage and rest at rocky bluffs within the timber as they make periodic excursions to the lick (Hebert and Cowan 1971). However, travel away from the safety of escape terrain and through forested habitats where vision is restricted (Festa-Bianchet et al. 1994, Côté and Beaudoin 1997) often increases the risk of predation. The effort expended by mountain goats to reach licks in spite of these risks emphasizes the importance of these licks to their ecology.

Alpine vegetation has low sodium and high potassium levels; thus, many populations of goats supplement their diets with minerals from licks (Hebert and Cowan 1971, Ayotte et al. 2006). While most early evidence pointed to sodium as the primary mineral obtained (to maintain sodium balance; Hebert and Cowan 1971), elevated levels of magnesium, manganese, iron,

\footnotetext{
${ }_{1}^{1}$ Aurora Wildlife Research, 1918 Shannon Point Rd. Nelson, British Columbia V1L 6K1, Canada.

2E-mail: kpoole@aurorawildlife.com

${ }^{3}$ Tembec Inc., Western Canada, Box 4600, Cranbrook, British Columbia V1C 4J7, Canada.

${ }^{4}$ Present address: CBA Ltd., Box 39, South Hazelton, British Columbia V0J 2R0, Canada.

${ }^{5}$ British Columbia Ministry of Environment, 205 Industrial Road G, Cranbrook, British Columbia V1C 7G5, Canada.
} 


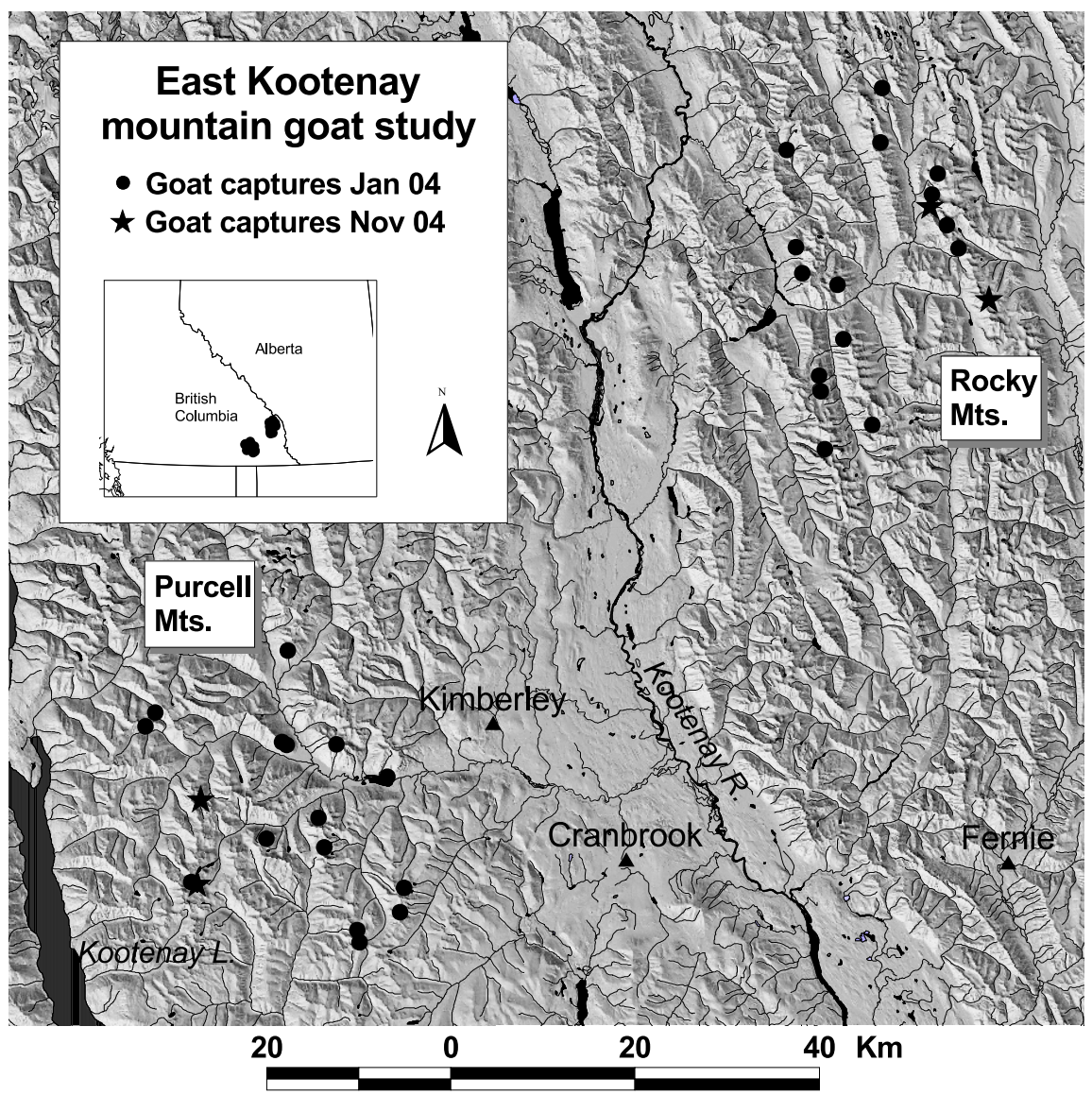

Fig. 1. Purcell Mountains and Rocky Mountains mountain goat study areas and capture locations, East Kootenay, British Columbia, January and November 2004.

and copper at lick sites have also been reported (Dormaar and Walker 1996, Ayotte et al. 2006). Supplemental sources of magnesium may help offset high dietary potassium levels, carbonates may help stabilize rumen $\mathrm{pH}$, and sodium may be especially important for lactating females (Bechtold 1996, Ayotte et al. 2006). Thus, licks are an extra source of essential minerals that can enhance buffering and absorption capacity (Kreulen 1985). Mineral licks can be any one of the following 3 types: dry-earth exposures, muck (wet) licks, and rock-face licks (Dormaar and Walker 1996).

Forestry development has the potential to impact lick use by altering vegetation along traditional trails, around rocky bluffs near licks, and at the licks themselves. Little is known about the potential impacts of such development on goats. Logged (or burned) areas around a lick site may benefit goats by providing more open sight lines, reducing predation risk and increasing forage supply. Alternatively, removal of forest cover through logging or wildfire may cause goats to abandon the site due to higher predation risk from loss of security cover. Very young early seral habitats provide less visual screening and may increase the number and proximity of deer (Odocoileus spp.), elk (Cervus elaphus), and moose, thereby attracting more predators, such as wolves (Canis lupus), cougars (Puma concolor), and bears (Ursus spp.). However, no published data are available to support these hypotheses (Côté and Festa-Bianchet 2003, Festa-Bianchet and Côté 2008).

Limited research on lick use by goats has been conducted within the East Kootenay area 
of southeastern British Columbia. Work conducted in the 1960s primarily involved assessment of licks relative to goat distribution and use (Hebert 1967, Hebert and Cowan 1971). In recent years, the Fish and Wildlife Compensation Program-Columbia Basin (FWCP-CB) has established a database on licks used by goats and other ungulates in East Kootenay (L. Ingham, FWCP-CB, Invermere, British Columbia, Canada, unpublished data). Forestry operations within the area have altered forest cover surrounding traditional travel routes to several known licks (K. Stuart-Smith, Tembec Inc., personal communication). Large wildfires and, in some cases, subsequent salvage logging have affected other well-used licks.

In this study, we examined lick use by 28 global positioning system (GPS) radio-collared mountain goats in 2 study areas. Our objectives for this portion of a larger study (Poole et al. 2009) were twofold: (1) to determine if GPScollar location data could be used to identify licks not previously known and (2) to document the characteristics, timing, and frequency of lick use by study animals. This information can be used to refine forestry development plans and develop guidelines to minimize impacts on lowelevation licks and on traditional trails to these licks.

\section{Methods}

\section{Study Areas}

We selected study areas within the Purcell Mountains (centered on the St. Mary River; $1800 \mathrm{~km}^{2}$ ) and within the Rocky Mountains (centered on the White River; $1450 \mathrm{~km}^{2}$; Fig. 1). The study areas were $65 \mathrm{~km}$ apart, separated by the Rocky Mountain Trench. In both areas the terrain was steep and rugged, with valley bottoms at 1000-1150 m and mountain peaks up to 2850-3200 m. Most goat habitat occurred in the Engelmann spruce-subalpine fir biogeoclimatic zone on valley slopes up to about 1700$2200 \mathrm{~m}$ elevation (depending upon aspect) and in the Alpine Tundra zone at the highest elevations (Meidinger and Pojar 1991, Braumandl and Curran 1992). Many of the valley bottoms in both areas had been commercially logged over the past 50 years, and large burns of varying ages occurred in portions of the Rocky Mountain study area. Goat numbers appeared to be stable or increasing in both areas.
Mountain Goat Capture and Monitoring

We deployed 15 GPS collars on goats in each study area in early January 2004, spreading search effort throughout our areas of interest on a number of individual ranges (Fig. 1). We attempted to equalize the number of male and female collared goats within each area. Four collars were redeployed in early November 2004 to replace animals that had died. Goats were captured by helicopter net-gunning (Barrett et al. 1982). We aged animals by counting the number of distinct horn annuli plus the fainter kid annulus formed at 6 months of age (Smith 1988, Stevens and Houston 1989). Each goat was fitted with a GPS collar (model G2000, Advanced Telemetry Systems, Isanti, MN) programmed to obtain a location every 6.25 hours (3.84 times daily). Capture and handling protocol followed the principles and guidelines of the Canadian Council on Animal Care (1993) and was conducted under British Columbia Ministry of Environment scientific permit DCB0913.

We monitored 10 females and 17 males (Purcell Mountains: 5 우, 7 $\widehat{\delta}$; Rocky Mountains:

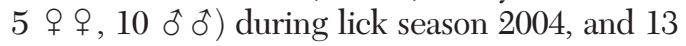
females and 16 males (Purcell Mountains: 7

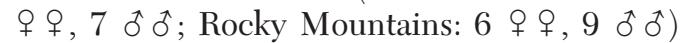
during lick season 2005. One male in each lick season in the Rocky Mountains was in areas not covered by orthophotos (see below) and was therefore removed from the analysis.

The collars were released from the animals in late August and early September 2005 by a remotely fired mechanism. The collars were recovered, and the data downloaded. Prior to analysis, we deleted locations with a positional dilution of precision $>10$ to remove major outliers (D’Eon and Delparte 2005). Mean GPSlocation error was assumed to be $11 \mathrm{~m}$ (D'Eon et al. 2002), likely within the range of accuracy of the habitat data we used. Quality of GPScollar data was high, with $88 \%$ location success and $83 \%$ three-dimensional fixes $(n=$ 53,675 GPS locations).

\section{Lick Identification}

We tracked goat movements by overlaying radio-collar data on recent orthophotos (Tembec Inc., Cranbrook, British Columbia, Canada), and we identified potential licks by identifying extrahome-range movements and use of low-elevation habitat. Because of the difficulty in using remote, digital data to determine why a goat 
utilizes a specific area at high elevation or within core home ranges, we could not readily distinguish higher-elevation licks from the other clusters of locations in those areas. Locations clustered spatially and temporally in areas distant from steep, rocky slopes (escape terrain) were marked as potential lick sites. Using these procedures, we identified 6 previously known licks and 10 suspected licks. We visited all known and suspected licks 30 May-3 June 2007. The area at and around each site was examined for evidence of lick use by goats. Evidence generally included goat hair snagged on roots under "lick trees," hair on trails, tracks, lower incisor marks in soil under trees, and scat. Trails and licks at each site were recorded using a GPS.

\section{Analysis}

For digital base data, we used 1:20,000scale terrain resources information management files (TRIM; Geographic Data BC 1992), 1:20,000-scale current forest inventory planning files (FIP; Resources Inventory Branch 1995), 1:20,000-scale georectified aerial photos (orthophotos), and the most recent timber-harvesting history with road coverage (Tembec Inc.). Forestry operability was defined using Tembec's standard operability line layer (last updated in 2004). The operable forest is the portion of the productive forest that is economically viable to harvest and, in this case, often bounded by steep terrain at upper elevations. Analyses were conducted using the ArcView geographic information system (ArcView 3.2a and 8.3, Environmental Systems Research Institute, Redlands, CA).

We examined lick use by year and by individual. We placed a 500-m-radius circle around the lick points and selected all relocations within that buffer to calculate arrival, departure, and duration of visit by each individual. If the $500-\mathrm{m}$ radius included a rocky staging bluff, the radius was decreased to exclude it so that any movements to and from the actual licks could be more accurately tabulated. Given approximately 6 hours between GPS-location attempts and some missed locations, the 500-m buffer appeared to be a reasonable compromise between detecting most visits to licks and not misclassifying movements around the broader area of the lick as lick visits. Goats could presumably travel $500 \mathrm{~m}$ to a lick on a good trail in minutes. Distance from the last core area used was calculated by examining the last concentration of goat locations and following points in sequence to the lick area using the ruler tool in ArcView. No distance was given if the goat remained in the immediate lick area for longer than approximately 1 week prior to lick use. Suspected travel in the vicinity of licks or through logging blocks en route to licks was examined using orthophotos and the timber-harvest data layer.

We obtained topographic and forest overstory information for each lick from our digital base data and calculated the distance to nearest logging block. We compared movement distances, the number of lick visits per year, and days spent at licks between males and females using nonparametric Wilcoxon's 2-sample tests because assumptions of normality were not met. We conducted data analyses using SAS software (SAS Institute, Cary, NC).

\section{REsults}

\section{Mineral Licks}

Of the 10 suspected lick sites visited, only one showed no evidence of being a lick. All 15 verified licks were of the dry-earth exposure type; one lick in the Purcell Mountains was a road surface. Most of the licks were characterized by numerous cavities (up to 40 at one site) dug under trees, which we termed "lick trees" (Fig. 2). Cavities ranged up to $2.2 \mathrm{~m}$ deep with entrance sizes up to $1 \mathrm{~m}$ in diameter. The cavities were often intertwined through and beneath the tree roots. Systematic documentation of the structure over lick cavities was not conducted, but the majority of approximately 100 lick sites we examined occurred under large-diameter trees, primarily live but also dead (less than approximately 10\%). These trees were mostly Douglas-fir (Pseudotsuga menziesii) or lodgepole pine (Pinus contorta), but use of a western redcedar (Thuja plicata) was also observed. Several licks were under juniper (Juniperus spp.) bushes. A very small proportion of lick cavities (less than approximately 3\%) were not under a tree or bush.

Licks were located at an average elevation of $1560 \mathrm{~m}(\mathrm{SE}=82$, range $980-2260 \mathrm{~m}, n=15)$, on an average slope of $32^{\circ}(\mathrm{SE}=3.5$, range $\left.12-53^{\circ}\right)$. Nine licks were on a south aspect, one on a west aspect, 3 on north aspects, and 2 on east aspects.

The habitat type immediately surrounding licks included walls of ephemeral drainage 


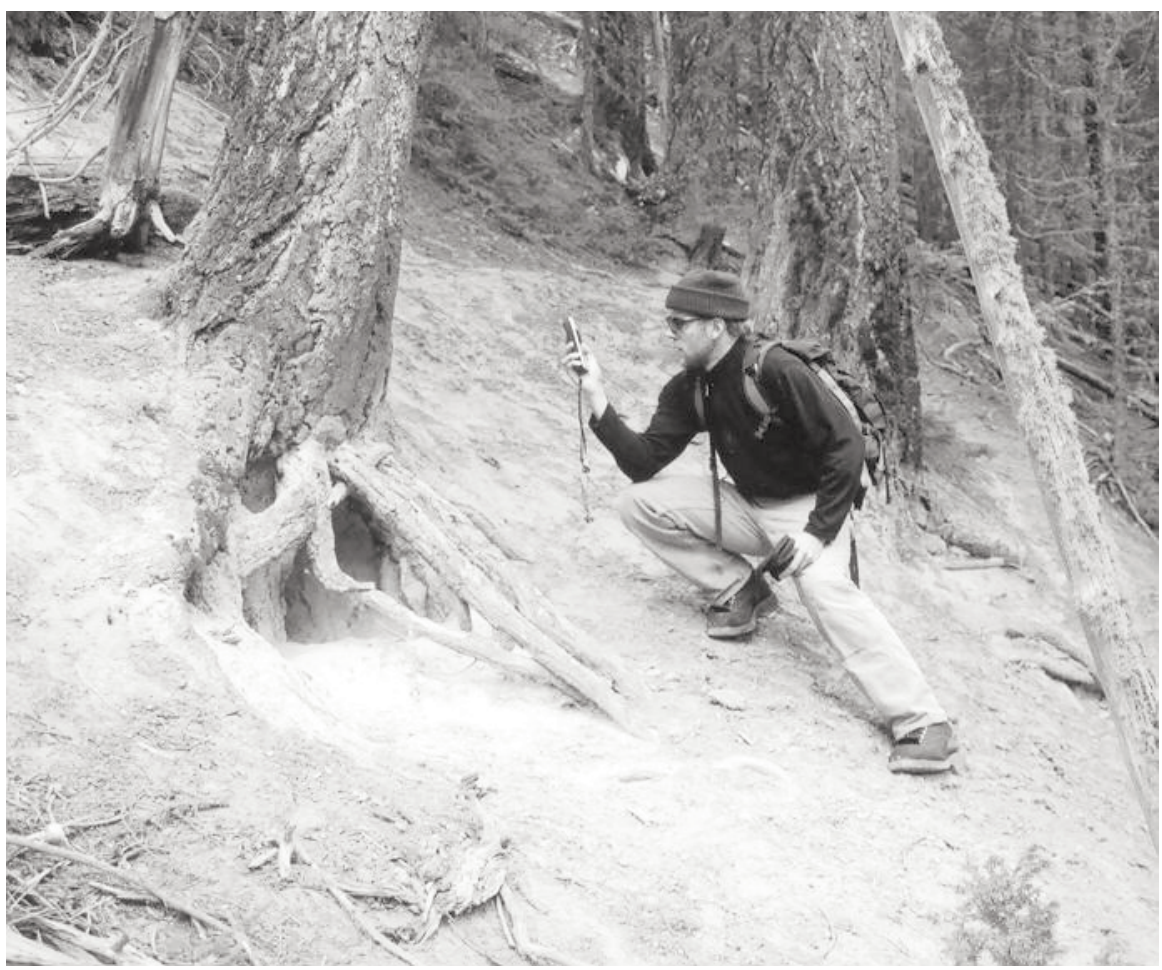

Fig. 2. K.D. Bachmann at a typical mineral lick in the Rocky Mountains study area, southern British Columbia, September 2004. Note how goats have excavated soil under the Douglas-fir trees.

gullies (6 licks), cutbanks and sloughs along rivers (3), road cutbanks (3), and other (3). Eight licks were in stands with no overstory data in the FIP database (mostly alpine, rock, and clearing descriptors). The other 7 sites with overstory data were in lodgepole pine $(n=4)$, Douglasfir $(n=2)$, and spruce-subalpine fir $(n=1)$ stands, with an average age of 131 years $(\mathrm{SE}=$ 13, range 96-213 years) and crown closure of $47 \%$ (SE $=7.5$, range $10-70 \%$.

Thirteen of the 15 licks were within potentially operable forests. Distance from licks to the closest logging block ranged from 45 to $7700 \mathrm{~m}$; however, all but 3 of the licks were $\leq 600 \mathrm{~m}$ from a logging block, and 5 licks were $<100 \mathrm{~m}$ away. Exposed mineral soils, natural or otherwise, were common at most licks. No goat locations occurred in logging blocks above 13 of the licks. In 2 cases, goats appeared to make some use of logging blocks on suspected access routes to licks, but in only one case were more than a few locations detected. Two or 3 goat locations were detected in logging blocks below or adjacent to 5 of the licks.

\section{Lick Use by Mountain Goats}

Of the 25 goats monitored in 2004, we detected lick use by 19 animals $(76 \%)$. Of the 27 goats monitored in 2005, we detected lick use by 19 animals $(70 \%)$. Note that these observations were primarily of lower-elevation licks detected from long-distance movements outside of the core area of normal alpine movements and may not reflect all lick use by the population. Number of visits to licks per season ranged from 0 to 9 , and there was a tendency for males (3.0 visits - year $^{-1}, \mathrm{SE}=0.55, n=29$ ) to have more visits than females $\left(1.7\right.$ visits $\cdot$ year $^{-1}, \mathrm{SE}=0.43, n=$ $23 ; Z=1.40, P=0.08)$. Goats often moved considerable distances to visit licks, up to $17.3 \mathrm{~km}$. No significant differences existed in the movement distances between sexes (males: $6360 \mathrm{~m}, \mathrm{SE}=618, n=58$, range $825-17,300$ $\mathrm{m}$; females: $5770 \mathrm{~m}, \mathrm{SE}=885, n=24$, range 1400-14,550 m; $Z=0.24, P=0.41)$.

We detected visits to licks between early February and mid-August (Fig. 3). Most visits by males occurred between early May and late June (median 9 June; mean 8 June, $\mathrm{SE}=2.5$ 


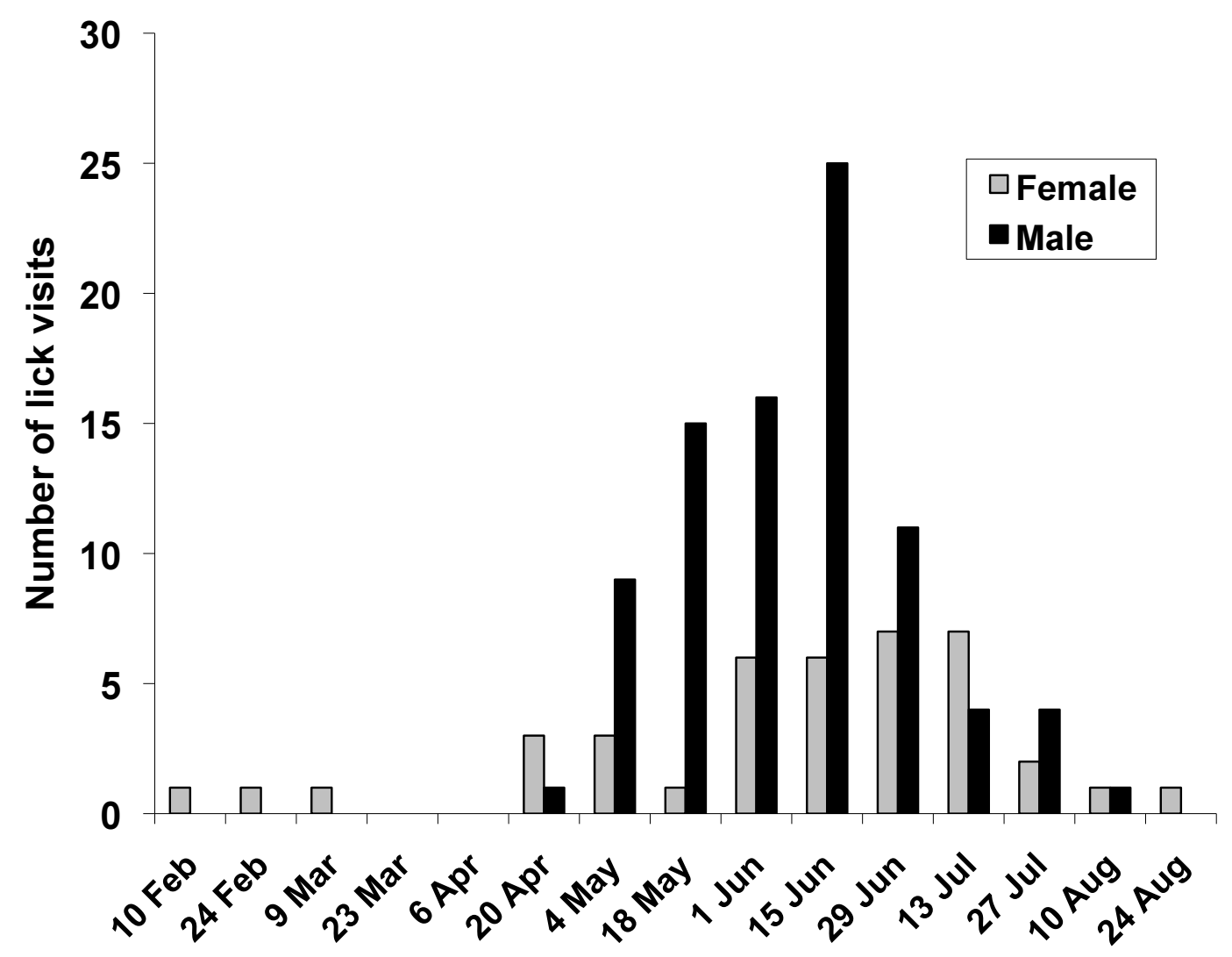

Fig. 3. Visits to mineral licks by female $(n=40)$ and male $(n=86)$ mountain goats by 2 -week periods in southeastern British Columbia, 2004-2005. Dates indicate the midpoint of each 2-week period.

days), and most visits by females occurred between early June and mid-July (median 18 June; mean 9 June, $\mathrm{SE}=6.8$ days). The same female made 3 visits to a previously known lick in February and March 2004. When these winter lick visits were removed, the median date of lick use by females shifted to 21 June (mean 18 June, $\mathrm{SE}=5.2$ days). Mean time spent at licks on each visit was 1.5 days for females $(\mathrm{SE}=0.19$, range $1-8$ days, $n=40$ ) and 1.6 days for males $(\mathrm{SE}=0.11$, range $1-6$ days, $n=86 ; Z=1.08$, $P=0.14)$.

Of 5 goat mortalities observed during the study, 2 (a male and a female) occurred nearly one year apart at the same lick, located $83 \mathrm{~m}$ from a logging block in the Rocky Mountain study area. These animals made multiple, extensive movements from mountain ranges to the west to visit licks within the drainage. Both mortalities occurred in late July and early August. Although predation was suspected in each case, the actual cause of death is not known.

\section{Discussion}

Using GPS-collar data, we detected significant low-elevation lick use by the majority of collared mountain goats. As verified in 2007, GPS-collar data were able to identify lowerelevation licks within the forest matrix not previously known to researchers-lick sites outside of the high-elevation habitats used by goats for most of the year. At our temporal scale (approximately 4 locations per day), long-distance and low-elevation movements stood out from core range areas and were identifiable as potential lick use. Use of high-elevation licks occurs in some populations (e.g., Poole and Heard 2003; C. Rice, Washington Department of Fish and Wildlife, personal communication), but it is difficult to determine using remote, 
digital data why a goat utilizes a specific area at high elevation or within core home ranges. Goat locations tend to be clustered throughout the year, focusing on escape terrain and cliff complexes. Collar data cannot be expected to readily distinguish higher-elevation licks from the other clusters of locations in those areas, unless they are shown as extra-home-range movements. While analysis of collar locations from a sample of collared goats should not be considered a complete inventory of licks in a study area, it seems to identify major lowerelevation licks used by animals in the area. To facilitate identification of licks, collar fix rates should be frequent enough (minimum of 3-4 fixes daily) to ensure that shorter temporal movements to licks are captured.

Our observations generally agree with the published literature on goat use of licks. We observed variation among individual goats in the number of lick visits, timing and duration of visits, and distance traveled to licks, similar to previous studies (Hebert and Cowan 1971, Singer and Doherty 1985, Hopkins et al. 1992, Klaus and Schmid 1998, Poole and Heard 2003). We observed males generally using licks earlier in the year than females. Although we detected lick use by a female goat in February and March, the majority of lick use occurred between mid-April and mid-August.

Our analysis should be considered somewhat conservative, given our GPS-location frequency and 500-m radius buffer used for quantifying lick use. For example, one female in the Rocky Mountains made two 10-11-km trips in July 2004 around the head of a drainage to licks that were detected using our 500-m buffer criteria. However, this goat also made an 11-km trip during 21-28 June 2004 to areas above 2 other known licks but had no lick use recorded during those dates, as no locations occurred within the 500-m radius buffer. Although the licks may not have been visited, it is possible that some short-duration lick use may have occurred during the June visit, which could have been detected with more-frequent collar fixes.

Distances traveled were often extensive, and some individuals visited a number of different licks. For example, 6 collared goats in the Rocky Mountains traveled up to $14 \mathrm{~km}$ to visit one particular lick; they inhabited the slopes immediately to the north of the lick from the beginning of May to midsummer in both years. In late July to mid-August each year, all of these goats left this area and returned to ranges to the northeast and east. Another male goat moved across 3 mountain ranges to visit all 5 identified licks in one drainage. Initial movements to licks in the spring were also often extensive. Over a 7-day period, one male moved $17.3 \mathrm{~km}$ along the entire length of a ridge to go directly to a lick. Hebert and Cowan (1971) observed movements by goats of 3-24 km between licks and alpine summer range in the same broad study area as our research.

We observed that the mean time spent at licks on each visit was roughly 1.5 days. Other ungulates tend to spend a much shorter time at licks (e.g., <2 hrs for elk and moose in northern British Columbia; Ayotte et al. 2008). Although mountain goats may tend to make longer, less frequent trips compared to elk and moose, because of the long distances from the goats' typical alpine habitat (Ayotte et al. 2008) to lick sites, our observations may have resulted from the relatively coarse temporal (approximately 4 locations per day) and spatial (500-m buffer) scales used in our study.

Use of licks is probably traditional, and use by a particular group of goats is subject to a number of factors. Previous work had identified 4 licks used by goats in Height of the Rockies Provincial Park (Ingham unpublished data). These licks were $<3.5$ to $4 \mathrm{~km}$ from 6 collared goats in our study, the same goats noted above that made extensive movements of up to $13-17 \mathrm{~km}$ to a lick. None of these collared goats appeared to use the 4 licks in Height of the Rockies Provincial Park because no locations were detected in the direction or vicinity of these licks. We do not know why these 4 licks were not used by our collared animals, as the licks did not appear to be in more risky areas. However, this finding suggests that traditional usage patterns may not include all licks within easy reach and that some licks may not provide the same minerals as others and are therefore ignored.

Many licks were in close proximity to logging blocks. It is unclear how proximity to forestry development affects goat survival and access to and use of low-elevation licks. We could not detect either preference or avoidance of logging blocks en route to licks, although we detected few locations of goats within these logged blocks. On a trail system and lick complex in the Ospika Valley in northern British Columbia, a 150-m forested buffer was left around the main trail to 
a lick. Subsequent goat use of the trail decreased and use of the adjacent logged blocks increased (to about half of total trips), with no apparent decline in overall use of the lick (M. Wood, FWCP-Peace/Williston, personal communication). A logging road bisecting the trail resulted in reduced movement rates for approximately one year. Movement appears to still occur in a dispersed fashion along a goat trail that cuts through an area logged in 2005 to a lick in the Purcell Mountains outside our study area (K. Stuart-Smith, Tembec Inc., personal communication). Thus, it is possible that goats may prefer the more open habitat of logged blocks when traveling to licks.

Two of 5 mortalities reported during our collaring study were at one lick in the Rocky Mountains, <100 m from a logging block. Goats experience increased predation risk at and below treeline (Festa-Bianchet et al. 1994, Côté and Beaudoin 1997). This risk may be compounded if logging blocks alter the predatorprey community at these low-elevation sites. Increases in early seral habitats may increase populations of deer, elk, and moose such that potential predators of goats (i.e., wolves, cougars, and bears; Côté and Festa-Bianchet 2003) may become more numerous near licks, resulting in goats being opportunistically preyed upon. Researchers in the Ospika study noted increased trail camera detections for moose, deer, and elk, as well as for bears and wolves, subsequent to logging in the area (Wood personal communication). A similar situation may be occurring for woodland caribou (Rangifer tarandus caribou) in British Columbia (Wittmer et al. 2005) and bighorn sheep in Alberta (Ross et al. 1997).

Trees may concentrate within their root systems minerals that are sought by goats. At all licks visited, goats appear to focus their soileating in and around the base of trees (Fig. 2). Hebert and Cowan (1971) noted that preferred sites at licks in southeastern British Columbia were composed of fine-textured soils usually among the roots of Douglas-fir trees. Although the reasons are unclear why goats appear to prefer sites under trees at low-elevation licks, harvesting of these sites would not only affect the physical dynamics of the site, but may also, in the long term, alter the quality of the soil goats ingested.

Several issues concerning goat lick use remain unresolved. Forestry operations may or may not disrupt lick use, and general lack of fine-scale movement data in most areas does not facilitate this kind of analysis, especially since traditional trail systems are unmapped at most licks. To detect fine-scale movements associated with lick use, an experimental study on disturbance of licks by forestry operations could employ more-frequent GPS-collar fixes, trail cameras, and data loggers. Also, certain licks seem to be especially important to goat ecology, as suggested by the long distances some individuals travel to access them, bypassing other, closer licks. Soil and chemical analysis of licks could elucidate if and/or why some licks are critical and could identify the most important sites in management plans.

\section{Conclusions}

Mineral licks are important to mountain goat ecology. This study demonstrated that GPScollar data can be used to identify previously unknown licks in an area. Goats traveled up to 17 $\mathrm{km}$ to visit licks. Most use occurred between mid-April and mid-August, with males using licks earlier than females. Some licks appeared particularly important to goats, judging by the distance moved and number of collared animals in attendance. Resource managers should be aware of and plan around goat-lick locations on the landscape.

No studies have examined the relationship between distance of licks to logging blocks and risk of mountain goat predation. Thus it is unknown what implications forestry development near licks may have for predation risk and goat fitness. Given the current concern about population risk to goats in parts of British Columbia (Ministry of Environment 2009), additional research on these questions would give managers valuable information for mitigating potential short- and long-term impacts from forestry on goat licks. Unless further information is available, it may be prudent not to harvest trees within and immediately adjacent to known licks.

While we acknowledge that we sampled lick use with a comparatively small number of collared goats, several geographical areas stood out as high importance. In particular, 2 areas in the Rocky Mountains study area had either a number of licks in a single drainage used extensively by goats in the area or a lick used by half a dozen collared goats that had traveled long distances. These areas have seen extensive forestry development, but any impacts on goat 
use of these licks are poorly understood. These licks are undoubtedly important to the local population and effective management strategies should be implemented at these and other licks identified in this study.

\section{ACKNOWLedgments}

Tembec Inc. through their Forestry Investment Account (FIA), the British Columbia Ministry of Environment (BC MoE), and the Habitat Conservation Trust Fund (HCTF) provided funding for this project, and we thank them for their generous support. This project was developed in collaboration with K. Stuart-Smith, Tembec Inc., and we thank her for insights and discussions. M. Belcher and T. Pachara, Tembec Industries, provided administrative support. We greatly appreciate L. Ingham and D. Lewis, FWCP-CB, for their efforts in capturing mountain goats and for sharing their mineral-lick database with us. C. Wilson, T. Vanderbrink, T. Macdonald, and B. Stewart, Bighorn Helicopters, ably captured goats under trying winter conditions. B. Phillips, BC MoE, and D. Pituskin, Tembec Inc., assisted with field checks in 2007. P. Homes, BC MoE, kindly made available orthophotos of the areas. D. Pritchard provided GIS outputs of lick sites. K. Stuart-Smith and 3 anonymous reviewers provided valuable comments on earlier drafts of this manuscript.

\section{Literature Cited}

Ayotte, J.B., K.L. Parker, J.M. Arocena, and M.P. GiLLINGHAM. 2006. Chemical composition of lick soils: functions of soil ingestion by four ungulate species. Journal of Mammalogy 87:878-888.

Ayotte, J.B., K.L. Parker, And M.P. Gillingham. 2008. Use of natural licks by four species of ungulates in northern British Columbia. Journal of Mammalogy 89:1041-1050.

BarRetT, M.W., J.W. Nolan, AND L.D. Roy. 1982. Evaluation of a hand-held net gun to capture large mammals. Wildlife Society Bulletin 10:108-114.

Bechtold, J.-P. 1996. Chemical characteristics of natural mineral springs in northern British Columbia, Canada. Wildlife Society Bulletin 24:649-654.

Braumande, T.F., and M.P. CurRan. 1992. A field guide for site identification for the Nelson Forest Region. B.C. Ministry of Forests, Victoria, British Columbia, Canada.

Canadian Council on Animal Care. 1993. Guide to the care and use of experimental animals. 2nd edition. Volume 1. Canadian Council on Animal Care, Ottawa, Ontario, Canada.

Côté, S.D., And C. BEAudoin. 1997. Grizzly bear (Ursus arctos) attacks and nanny-kid separation on mountain goats (Oreamnos americanus). Mammalia 61:614-617.
Côté, S.D., And M. Festa-Bianchet. 2003. Mountain goat. Pages 1061-1075 in Wild mammals of North America: biology, management, and conservation. G.A. Feldhamer, B. Thompson, and J. Chapman, editors, Johns Hopkins University Press, Baltimore, MD.

D’Eon, R., AND D. DELPaRTE. 2005. Effects of radio-collar position and orientation on GPS radio-collar performance, and the implications of PDOP in data screening. Journal of Applied Ecology 42:383-388.

D’Eon, R.G., R. Serrouya, G. Smith, and C.O. Kochanny. 2002. GPS radiotelemetry error and bias in mountainous terrain. Wildlife Society Bulletin 30:430-439.

DORMAAR, J.F., AND B.D. WALKER. 1996. Elemental content of animal licks along the eastern slopes of the Rocky Mountains in southern Alberta, Canada. Canadian Journal of Soil Science 76:509-512.

Festa-Bianchet, M., AND S.D. Côté. 2008. Mountain goats: ecology, behavior, and conservation of an alpine ungulate. Island Press, Washington, DC.

Festa-Bianchet, M., M. Urquhart, and K.G. Smith. 1994. Mountain goat recruitment: kid production and survival to breeding age. Canadian Journal of Zoology $72: 22-27$.

Geographic Data BC. 1992. British Columbia specifications and guidelines for geomatics. Content series volume 3: digital baseline mapping at 1:20,000. Release 2.0. British Columbia Ministry of Environment, Lands and Parks, Victoria, British Columbia, Canada.

Glasgow, W.M., TC. Sorensen, H.D. Cark, and K.G. SMITH. 2003. Management plan for mountain goats in Alberta. Fish and Wildlife Division, Alberta Sustainable Resource Development, Edmonton, Alberta, Canada.

Hebert, D., AND I.M. CowAn. 1971. Natural salt licks as a part of the ecology of the mountain goat. Canadian Journal of Zoology 49:605-610.

Hebert, D.M. 1967. Natural salt licks as a part of the ecology of the mountain goat. Master's thesis, University of British Columbia, Vancouver, British Columbia, Canada.

Hopkins, A., J.P. Fitzgerald, A. Chappell, and G. Byrne. 1992. Population dynamics and behavior of mountain goats using Elliot Ridge, Gore Range, Colorado. Biennial Symposium of the Northern Wild Sheep and Goat Council 8:340-356.

Jones, R.L., And H.C. Hanson. 1985. Mineral licks, geophagy, and biochemistry of North American ungulates. Iowa State University, Ames, IA.

KLAUS, G., AND B. SCHMID. 1998. Geophagy at natural licks and mammal ecology: a review. Mammalia 62:481-497.

KREulEN, D.A. 1985. Lick use by large herbivores: a review of benefits and banes of soil consumption. Mammal Review 15:107-123.

Meidinger, D., and J. Pojar. 1991. Ecosystems of British Columbia. Special Report Series 6, B.C. Ministry of Forests, Research Branch, Victoria, British Columbia, Canada.

Ministry of Environment. 2009. Conservation framework. BC Ministry of Environment Conservation Framework; [cited 1 May 2009]. Available from: http:// www.env.gov.bc.ca/conservationframework/results .html\# outputs

Poole, K.G., AND D.C. Heard. 2003. Seasonal habitat use and movements of mountain goats, Oreamnos americanus, in east-central British Columbia. Canadian Field-Naturalist 117:565-576. 
Poole, K.G., K. Stuart-Smith, And I.E. Teske. 2009. Wintering strategies by mountain goats in interior mountains. Canadian Journal of Zoology 87:273-283.

Resources Inventory Branch. 1995. Relational data dictionary (RDD) 2.0. British Columbia Ministry of Forests, Victoria, British Columbia, Canada.

Ross, P.I., M.G. Jalkotzy, and M. Festa-Bianchet. 1997. Cougar predation on bighorn sheep in southwestern Alberta during winter. Canadian Journal of Zoology 75:771-775.

Singer, F.J., AND J.L. DoherTy. 1985. Movements and habitat use in an unhunted population of mountain goats, Oreamnos americanus. Canadian Field-Naturalist 99: 205-217.

SмITH, B.L. 1988. Criteria for determining age and sex of American mountain goats in the field. Journal of Mammalogy 69:395-402.

Stevens, V., And D.B. Houston. 1989. Reliability of age determination of mountain goats. Wildlife Society Bulletin 17:72-74.
Tankersley, N. 1984. Mineral lick use by Dall sheep in the Watana Creek Hills, Alaska. Proceedings of the Northern Wild Sheep Goat Council 4:211-230.

Tankersley, N.G., and W.S. Gasaway. 1983. Mineral lick use by moose in Alaska. Canadian Journal of Zoology 61:2242-2249.

WatTs, T.J., AND S.D. SchEmnitZ. 1985. Mineral lick use and movement in a remnant desert bighorn sheep population. Journal of Wildlife Management 49:994-996.

Wittmer, H.U., A.R.E. Sinclair, and B.N. McLellan. 2005 . The role of predation in the decline and extirpation of woodland caribou. Oecologia 144:257-267.

Received 8 May 2009 Accepted 4 December 2009 